\title{
LA ANEXIÓN DE CRIMEA: UNA RESPUESTA A LA CRISIS DEMOGRÁFICA DE LA FEDERACIÓN RUSA
}

Daniel AÑorve AÑorve

\section{INTRODUCGIÓN}

UnO DE LOS EVENTOS GeOPOLíticos que gozarán de considerable atención en los años venideros es la reciente anexión de Crimea por parte de La Federación Rusa. Dicha anexión confirma lo que Timor Oriental (2002), Kosovo (2008), Osetia del Sur (2008), Abjasia (2008) y Sudán del Sur (2011) habían planteado después del fin de la Guerra Fría: los cuestionamientos y cambios fronterizos no habrían de detenerse como resultado del fin de la disputa político-ideológica del siglo xx. Tampoco las olas democratizadoras lograron alterar significativamente las ancestrales disputas geopolíticas.

La anexión de Crimea a inicios de 2014 ha generado una gran variedad de explicaciones, como la personalidad de Putin, ${ }^{1}$ el intento por restablecer la Unión Soviética, la respuesta al encirclement ruso que la expansión sin fin de la Organización del Tratado del Atlántico Norte (OTAN) significa, el intento de atracción de la economía y el mercado ucraniano hacia la órbita de la Unión Europea (UE), la simple culpa de la Federación Rusa, ${ }^{2}$ entre otras. Sin duda,

${ }^{1}$ Ben Shapiro, "Putin's Next 4 Targets", Breitbart (online), 18 de marzo de 2014, en http://www.breitbart.com/national-security/2014/03/18/putin-four-inva sions/ (consultado el 29 de noviembre de 2014). Cfr. John Mearsheimer, "Why the Ukraine Crisis Is the West's Fault", Foreign Affairs, vol. 93, núm. 5, septiembre-octubre de 2014, pp. 1-12.

${ }^{2}$ Cfr. John Mearsheimer, art. cit. 
no existe una explicación monocausal, por lo cual tratar de validar alguna de las aproximaciones descartando las demás resulta incorrecto. Partiendo de una revisión del tratamiento que algunos realistas han dado a la población, el presente artículo ofrece una explicación adicional, desde lo que llamaremos "realismo demográfico”, que sin pretender descartar las explicaciones ya mencionadas bien podría dar nueva luz al entendimiento de la anexión, al tiempo que ayudar a entender futuros escenarios bajo los cuales sea posible una ulterior expansión territorial rusa. La bibliografía realista presenta diversas referencias en torno a la importancia de la población como elemento del poder de un Estado; sin embargo, no siempre se ha puesto el énfasis suficiente en el papel de ésta. En ocasiones, el papel de la población queda oculto o subordinado al rol que juega dentro de la economía. Adjetivar el realismo, como lo hacemos al hablar de un realismo demográfico, permite devolver a éste, al menos cualitativamente, parte del poder explicativo que puede haber perdido cuando se usa, lo que es un poderoso enfoque, de manera genérica. Así pues, el uso adjetivado del realismo le brinda nuevas posibilidades. Sin pretender edificar una nueva teoría derivada del realismo, lo que en este artículo se presenta como realismo demográfico ayuda a devolver la centralidad que la cuestión demográfica merece dentro del análisis de la expansión territorial rusa en 2014, y a vaticinar futuros escenarios.

La aproximación de este artículo, para su cabal comprensión, requiere de un análisis de la demografía rusa heredada de la Unión Soviética y de su evolución durante poco más de dos décadas de vida independiente del Estado ruso. Por lo tanto, el estudio explica la crisis poblacional que empezó hacia los últimos años de la era soviética y que se ha profundizado en la era post-soviética. Importante mención merece lo sucedido con la emigración que siguió a la disolución de la URSS, por un lado, y la inmigración hacia la Federación Rusa en años recientes.

La anexión de Crimea es planteada en este trabajo como una solución a varios problemas: a la crisis poblacional, a cuellos de botella militares, a preocupaciones y dilemas en la política migratoria, a los problemas de la ampliación del mercado doméstico y regional, a los problemas fiscales, así como al rol que Osetia del 
Sur, Abjasia y ahora Crimea juegan como una doble reserva territorial y poblacional para el país.

En el último apartado se analiza el rol que podrían jugar, por un lado, la Unión Económica Euroasiática (UEE), como posible solución no territorial a la crisis demográfica, y, por otro lado el papel que Occidente podría tener al aceptar el "no entorpecimiento" de dicha Unión como solución de corto y mediano plazo a la expansión territorial rusa.

\section{EXPLICACIONES EN TORNO A LA ANEXIÓN RUSA DE CRIMEA}

Desde la crisis con Georgia en 2008, y quizá antes, con motivo de las guerras del gas, ha sido común el análisis de la geopolítica rusa como resultado de la personalidad de su líder, Vladimir Putin. ${ }^{3} \mathrm{La}$ propensión de Putin a violar el derecho internacional también es frecuentemente invocada por los analistas occidentales. Por ejemplo, Michael Crowley y Simon Shuster ${ }^{4}$ consideran que Putin de forma unilateral ha reafirmado el derecho ruso de proteger a sus conciudadanos fuera de la Federación Rusa, lo cual es una afrenta al orden de post Guerra Fría. Strobe Talbott, presidente de la Brookings Institution, argumenta que Putin ha hecho del chauvinismo y del irredentismo la base de la política rusa. ${ }^{5}$ Otra explicación, verbalizada por el primer ministro ucraniano, Arseny Yatseniuk, es la del intento de restauración de la Unión Soviética. ${ }^{6}$

Una explicación menos enfocada en las personas es la tesis del encirclement. Crowley y Shuster advierten sobre el malestar que la

${ }^{3}$ Cfr. Karen Dawisha, Putin's Kleptocracy: Who Owns Russia, Simon \& Schuster, 2014; Cfr. Masha Gessen, The Man Without a Face: The Unlikely Rise of Vladimir Putin, Riverhead Trade, 2013.

${ }^{4}$ Michael Crowley y Simon Shuster, "This Is War", Time, 19 de mayo de 2014, pp. 31-35.

${ }^{5}$ Michael Crowley y Simon Shuster, art. cit.

${ }^{6}$ Citado en Daryna Krasnolutska y Kateryna Choursina, "Ukraine Leader Says Putin Seeks to Restore Soviet Union”, Bloomberg News, 13 de septiembre de 2014, en http:/ / www.businessweek.com/news/2014-09-12/u-dot-s-dot-widens-sanctionson-russian-banks-energy-defense-firms (consultado el 24 de octubre de 2014). 
expansión de la otan, la cual incluyó a Polonia y los Estados del Báltico, provocó en Putin. Tal sentimiento fue expresado en marzo por Putin a la Duma: "La otan sigue siendo una alianza militar y nosotros estamos en contra de tener una alianza militar sintiéndose en casa justo en nuestro patio trasero o en nuestro territorio histórico".7

Por su parte, los editores de The Nation advierten sobre cómo la reciente modificación de fronteras rusas es el fruto amargo de un arreglo profundamente fallido de la post Guerra Fría, que se parece más a Versalles que a Bretton Woods. ${ }^{8} \mathrm{El}$ actual arreglo ha generado inflamación por la decisión miope estadounidense de expandir la OTAN hacia el Este y perseguir otras políticas destinadas a aislar a la Federación Rusa, al tiempo que se han ignorado los intereses de ese país. Mearsheimer también se adhiere a quienes consideran que la expansión de la OTAN por parte de Estados Unidos y de sus aliados europeos carga con la mayor parte de la responsabilidad por la crisis ucraniana-rusa, al tratar de integrar a Ucrania dentro de la órbita occidental. ${ }^{9}$ Mearsheimer considera legítima la reacción rusa al prevenir que Occidente maniobre en su 'patio trasero' y considera legítima la preocupación rusa por defender sus intereses vitales.

La intervención de la OTAN en Kosovo ha servido a la Federación Rusa como un precedente legal para la toma militar y constitucional de una provincia de un Estado vecino. El National Review destaca que incluso especialistas conservadores en derecho internacional, ${ }^{10}$ como Jeremy Rabkin, advirtieron en ocasión de las acciones en Kosovo sobre la violación legal del principio de la no-intervención en los asuntos internos de un Estado soberano, acción que podría tener un efecto búmeran para Estados Unidos.

Stephen Walt también considera que la raíz del conflicto Federación Rusa-Ucrania está en las invasiones históricas sufridas por la

${ }^{7}$ Citado en Michael Crowley y Simon Shuster, op. cit., p. 33.

8 "Time for Realism and Common Sense on Ukraine", The Nation, 24 de marzo de 2014.

${ }^{9}$ Mearsheimer, "Why the Ukraine Crisis Is the West's Fault", Foreign Affairs, vol. 93, núm. 5, septiembre-octubre de 2014, pp. 1-12.

${ }^{10}$ National Review, "Putin's Perilous Overreach", 7 de abril de 2014. 
primera, lo cual ha causado una alta sensibilidad a las acciones de sus vecinos. Para Walt, es claro que la Federación Rusa ha sentido por un largo tiempo que Estados Unidos promueve el constante movimiento de las instituciones occidentales dentro de su esfera de influencia, en especial desde el colapso de la URSS. ${ }^{11}$ De hecho, Walt considera que la invasión rusa a Georgia fue una forma de enviar un mensaje a Occidente de que la ulterior expansión de la OTAN hacia el Este sería resistida por la Federación Rusa por cualquier medio necesario. ${ }^{12}$

No sólo es el crecimiento de la otAn lo que preocupa a la Federación Rusa, sino también el ensanchamiento de la uE, lo cual es percibido por los líderes rusos como el caballo de Troya para la expansión de la OTAN. ${ }^{13}$ Tales expansiones también han cuestionado la ingeniería social rusa y de otros Estados del espacio post-soviético, y con esto la autodeterminación de los Estados resultantes. Mearsheimer explica cómo el apoyo de Occidente de las revoluciones de colores, como la Revolución Naranja en Ucrania en 2004 y en 2014, en Maidan, han ocasionado reacciones negativas en la clase política rusa. Por su parte, Carl Gershman escribió en septiembre de 2013 en The Washington Post: "Los rusos también enfrentan una decisión y Putin mismo puede hallarse en el bando perdedor, no sólo en el Cercano Extranjero sino dentro de Rusia misma". ${ }^{14}$ Mearsheimer también documenta el interés de personajes tan influyentes como John McCain y del embajador estadounidense en Ucrania, Geoffrey Pyatt, y denuncia la participación de éstos en el golpe a Yanukovich. Respecto al embajador, recupera sus palabras el día de la caída de Yanukovich: "fue un día para los libros de historia". ${ }^{15}$

Entre la miríada de posibles explicaciones que dan cuenta de la anexión rusa de Crimea, la última interpretación común que se

${ }^{11}$ Stephen Walt, "Why Arming Kiev Is A Really, Really Bad Idea", Foreign Policy, 9 de febrero de 2015.

12 Ibid.

${ }^{13}$ John Mearsheimer, art. cit.

${ }^{14}$ Carl Gershman, "Former Soviet States Stand Up to Russia. Will the U.S.?", The Washington Post, 26 de septiembre de 2013.

${ }^{15}$ Citado en John Mearsheimer, art. cit., p. 5. 
maneja en esta sección, antes de abordar la explicación propia, es aquella que señala que la crisis ucraniana fue resultado de la intromisión europea y de decisiones de la derecha ucraniana que ponían en riesgo la formación del principal objetivo de política exterior rusa, es decir, la formación de la Unión Económica Euroasiática.

\section{LOS ELEMENTOS DE PODER SEGÚN LA REALPOLITIK}

Para Christopher Spencer es claro que la situación en Crimea demuestra que el realismo político sigue siendo la teoría dominante que gobierna las relaciones internacionales en la actualidad. ${ }^{16}$ Bajo esta lógica, cuando los principios de la negociación, la cooperación, etc., entran en conflicto con conceptos como el interés nacional y la expansión del poder, casi siempre pierden los primeros. Bien reconocen los editores de The Nation que a pesar de que a la prensa occidental le gusta negar los intereses de los adversarios y distorsionar los contextos, con lo cual han convertido a Putin en el villano, la realidad geopolítica indica que Ucrania es central para la seguridad rusa, por lo cual la expansión de la OTAN, así como un potencial desplazamiento de las bases rusas en Ucrania o bien la acogida de la flota estadounidense o de la отAN en el mar Negro, no pueden ser considerados como miedos irracionales. Al respecto, los editores de The Nation recuerdan que, no obstante las promesas de George H. Bush de no extender la alianza noratlántica, ocho ex miembros del Pacto de Varsovia y los Estados del Báltico han sido incorporados a la oTAN, e incluso se ha utilizado a Georgia como puesto de avanzada militar. Los editores se cuestionan sobre lo que pensaría cualquier administración estadounidense acerca de la decisión de México de entablar una alianza militar con la Federación Rusa. ${ }^{17}$

${ }^{16}$ Christopher Spencer, "Crimea Proves Political Realism Is Still Dominant", Guardian Liberty Voice, 23 de marzo de 2014.

17 "Time for Realism and Common Sense on Ukraine", The Nation, 24 de marzo de 2014. 
Dentro del ajedrez de la geopolítica del siglo Xxi, no sólo es la Federación Rusa la que se conduce según los designios del realismo. Crowley y Shuster notan que tanto Alemania, producto de Nordstream, ${ }^{18}$ como Francia, producto de la venta de un porta-helicópteros a la Federación Rusa, han relejado las sanciones originalmente contempladas o impuestas a dicho país. ${ }^{19}$

Si se parte de la premisa de que el realismo sigue vigente en el siglo XXI, ${ }^{20}$ es preciso hacer un breve repaso por algunos de sus postulados. La intención es encontrar dentro de éstos las referencias a la demografía como componente central del poder de los Estados. A mediados del siglo xx, Hans Morgenthau aseguraba que los componentes del poder nacional incluían: la geografía, los recursos naturales, la capacidad industrial, la presteza militar, la población, el carácter nacional, la moral nacional, la calidad de la diplomacia y la calidad del gobierno. ${ }^{21}$ La población era contabilizada por Morgenthau dentro de los elementos constantes del poder. Morgenthau otorgaba un valor especial a la población, pues advertía que se requiere una gran población para el control efectivo del territorio, para operar la industria, la agricultura y para montar un ejército.

Paul Kennedy también identifica una clara conexión entre el auge y caída económica de una gran potencia y su crecimiento y declive como una potencia militar importante (o como un poder mundial).$^{22}$ Es claro que, como veremos más adelante con

18 Se trata de un importante gasoducto que lleva petróleo desde la Federación Rusa hacia Europa Occidental, evitando pasar por países con los que la Federación Rusa ha tenido históricos problemas geoestratégicos.

${ }^{19}$ Michael Crowley y Simon Shuster, art. cit.

${ }^{20}$ Los realistas encontrarían estéril la discusión sobre la "vigencia" del realismo, toda vez que parten, en su versión clásica, de la naturaleza humana y sus versiones estructurales, de la naturaleza del sistema (anárquico). Por lo tanto, al tratarse de naturalezas, ya sea humana o estructural, es poco probable que pierda su vigencia.

${ }^{21}$ Hans Morgenthau, Politics among Nations: The Struggle for Power and Peace, Nueva York, Knopf, 1948.

${ }^{22}$ Paul Kennedy, The Rise and Fall of great Power: Economic Change and Military Conflict from 1500 to the Present, Nueva York, Random House, 1987. 
Mearsheimer, ${ }^{23}$ un gran PIB requiere de una gran población; entonces también el declive de una potencia militar puede ser una consecuencia de una población decreciente.

Kenneth Waltz, al inicio del orden emergente de la post Guerra Fría, también otorgaba un valor importante a la población. ${ }^{24}$ Por un lado, Waltz consideraba que tanto la URSS como su sucesor, la Federación Rusa, eran importantes actores internacionales, no sólo gracias al formidable poder militar, sino a una combinación de factores, entre los que destacaban: el tamaño de la población, el territorio, la dotación de recursos. El autor listaba otros factores que la Federación Rusa no tuvo en su momento, pero que hoy, bajo Putin, contempla, como la capacidad económica y la estabilidad política; y otro, que aunque debatible no cuenta con él, la competencia (por lo menos comercial). El punto es que para Waltz, al igual que antes para Morgenthau, el tamaño de la población es un punto medular del poderío nacional. Es en parte gracias al tamaño de la población que Waltz incluye a China, Japón o algún Estado de Europa Occidental como Alemania, como candidatos a grandes potencias al finalizar la Guerra Fría, aunque reconocía que no hay un solo elemento que sin la combinación con otros pueda por sí mismo levantar a un Estado hacia el estatus de gran potencia. Waltz alegaba que dada la imposibilidad de convertirse en una gran potencia por el solo hecho de tener armas nucleares, otros elementos, como los que tiene la Federación Rusa, una gran población, un vasto territorio y considerables recursos naturales, pueden compensar ciertas debilidades. La Federación Rusa, con su tamaño, su población y su posición geográfica está llamada a ser una gran potencia defensiva. Años después, en una entrevista, Waltz $^{25}$ consideraba a China y la India, ambas indiscutibles potencias demográficas, como las grandes potencias en el horizonte. Al

${ }^{23}$ John Mearsheimer, The Tragedy of Great Power Politics, Nueva York, W.W. Norton \& Company, 2001.

${ }^{24}$ Kenneth Waltz, "The Emerging Structure of International Politics", International Security, vol. 18, núm. 2, otoño de 1993, pp. 44-79.

${ }^{25}$ Véase Luis Simon, "Interview with Kenneth Waltz”, 15 de marzo de 2013, en http:/ /www.europeangeostrategy.org/2013/03/interview-kenneth-waltz/ (consultado el 24 de octubre de 2014). 
igual que Mearsheimer, advertía que la Federación Rusa ha dejado de serlo.

Mearsheimer, como otros realistas que lo precedieron, argumenta que el poder está basado en las capacidades materiales particulares que un Estado posee. El autor divide el poder en dos tipos: el poder latente y el poder militar. El poder latente se refiere a los ingredientes socio-económicos que conlleva la construcción de un poder militar. El poder latente tiene como base la riqueza del Estado y el tamaño de la población. Mearsheimer asegura que el poder latente es muy importante para los Estados ya que una riqueza abundante y una gran población son los prerrequisitos para construir una fuerza militar formidable. ${ }^{26}$ Para Mearsheimer, el tamaño de la población cuenta y mucho, ya que las grandes potencias requieren de grandes armadas, mismas que sólo pueden formarse en países con grandes poblaciones. El autor advierte que los Estados con pequeñas poblaciones pueden ser ricos, pero no grandes potencias. La importancia de contar con una gran población para Mearsheimer no sólo es militar, sino económica, toda vez que el otro componente del poder latente es la riqueza. Mearsheimer sostiene que sólo las grandes poblaciones pueden producir gran riqueza, el otro bloque del poder militar. ${ }^{27}$

Mearsheimer observa que no toda gran población asegura una gran riqueza, pero una gran riqueza sí requiere invariablemente de una gran población. ${ }^{28} \mathrm{Al}$ analizar la crisis Federación Rusa-Ucrania, Mearsheimer ${ }^{29}$ advierte que la Federación Rusa no es una potencia en ascenso, sino una potencia en declive, especialmente por dos razones: por su demografía y por su economía unidimensional. Dadas estas realidades, el autor juzga innecesario contener a la Federación Rusa, al tiempo que considera que la postura occidental sólo incentiva a la Federación Rusa a comportarse de forma violenta.

Incluso Fareed Zakaria, con su realismo no estructural sino centrado en el Estado, no niega los componentes materiales del

\footnotetext{
${ }^{26}$ Mearsheimer, The Tragedy of Great Power Politics.

27 Ibid., p. 61.

${ }^{28}$ Ibid., p. 62.

${ }^{29}$ Loc. cit.
} 
poder, no obstante considerar que el análisis del poder estatal vs. el poder nacional es clave para entender la política internacional. ${ }^{30}$ $\mathrm{Al}$ advertir que el poder del Estado es una función del poder nacional, Zakaria reconoce que el Estado extrae su poder del poder nacional para sus fines. Entonces, aun cuando los hombres de Estado pueden usar de diversas maneras los recursos de poder de los que dispone la nación, se requieren los beneficios que, como los otros realistas reconocen, da el contar con una gran población.

Para concluir el presente apartado, Nicholas Eberstadt advierte que la crisis poblacional es tal que dados los patrones demográficos tan anormales y peligrosos, el Kremlin ha introducido nuevos y ambiciosos programas con el fin de revertir la espiral demográfica descendente. Entre los programas está el otorgar diez mil dólares en créditos y subsidios a las madres que tengan un segundo o un tercer niño. Los resultados han logrado aliviar un poco el colapso poblacional. ${ }^{31}$ Lo que parece un hecho para Rosstat, ${ }^{32}$ incluso ante los escenarios más optimistas, es que una mayor caída de la población sólo puede ser detenida por medio de la migración masiva desde el exterior. ${ }^{33}$ Este artículo plantea que, como resultado de que la migración masiva desde el exterior ha sido inhibida por diversos factores, el Estado ruso impulsó su reemplazo en 2014, por otros medios, es decir en forma de la anexión de Crimea. La desesperada medida del Kremlin, disfrazada en una retórica de reivindicación histórico-nacionalista, puede ser entendida siguiendo la advertencia de María Lodahl, al señalar la doble tendencia demográfica rusa, al declive de la población y al envejecimiento de ésta: "Rusia percibe esto no sólo como una amenaza económica, sino también como una amenaza geopolítica”. ${ }^{34}$ De esto trata principalmente el presente artículo.

${ }^{30}$ Fareed Zakaria, From Wealth to Power: The Unusual Origins of America's World Role, Princeton, Princeton University Press, 1998.

31 Nicholas Eberstadt, “The Dying Bear”, Foreign Affairs, vol. 90, núm. 6, noviembre-diciembre de 2011, pp. 95-108.

${ }^{32}$ La agencia estatal rusa de Estadística.

${ }^{33}$ Eberstadt, art. cit.

${ }^{34}$ María Lodahl, "Russia: Demographic Trends Pose Economic Problems", Economic Bulletin, vol. 37, núm. 8, agosto de 2000, p. 262. 


\section{Peculiaridades de la demografía Rusa}

No son sólo los realistas los que hablan de la centralidad de la población; también, y más importante aún, la clase política en la Federación Rusa se ha dado cuenta de la primacía que tiene la situación demográfica del país. Al respecto, Eberstdat considera: "Quizá entre todos los acontecimientos dolorosos de la sociedad rusa, desde el colapso soviético, el más sorprendente de todos -el más desalentador- es el del declive demográfico del país. En las dos décadas pasadas, Rusia ha sido atrapada por una devastadora y altamente anómala crisis poblacional en tiempos de paz". ${ }^{35}$

Eberstadt añade que esta crisis amenaza la perspectiva económica, las ambiciones de modernización y desarrollo, e incluso la seguridad de la Federación Rusa. De hecho, en 2007, el ex primer ministro ruso, Sergei Stepashin advertía que "la reducción en el tamaño de la población y la reducción de la densidad de población [...] generará el peligro de debilitar la influencia política, económica y militar rusa en el mundo". ${ }^{36}$

Siete años antes de la declaración de Stepashin, en julio de 2000, el presidente Putin alertaba sobre la amenaza de que la Federación Rusa se convirtiera en un país senil. En el mismo año, en su primer informe a la nación, Putin describió la situación demográfica del país como "alarmante" al tiempo que advertía que "la supervivencia del país estaba en riesgo". ${ }^{37}$

En enero de 2005, el Consejo de Seguridad de la Federación Rusa consideraba el declive poblacional como "catastrófico" y notaba que podría incluso reducir en una tercera parte la población rusa para mediados del siglo en curso. ${ }^{38}$ Posteriormente, Putin, en 2006, durante su informe de gobierno identificó la demografía como "el problema más grave que enfrenta el país actualmente". ${ }^{39}$ Más adelante, en la Estrategia de Seguridad Nacional de 2009,

35 Nicholas Eberstadt, art. cit., p. 95.

36 Ibid., p. 105.

${ }^{37}$ Maria Lodahl, art. cit., p. 255.

38 Cfr. Tom Parfitt, "Russia's Population Crisis", The Lancet, vol. 365, 26 de febrero de 2005, p. 743.

${ }^{39}$ Nicholas Eberstadt, art. cit., p. 107. 
durante la administración de Dmitri Medvédev, la situación demográfica rusa se contemplaba como una de las "nuevas amenazas a la seguridad" del país. ${ }^{40}$

Lo anterior, por lo que respecta a declaraciones de hombres de Estado. La relevancia de la demografía también ha sido objeto de estudio de los académicos rusos. Por ejemplo, Leonid Rybakovskii observa: "Desde la década de 1990 y hasta mediados de la primera década del siglo xxi, en todos los lugares de Rusia, salvo unas cuantas regiones en el Cáucaso Norte, ${ }^{41}$ se experimentó un declive poblacional". ${ }^{42}$ Esto llevó a que para inicios de 2006 la población del país fuera menor en seis millones de habitantes respecto a la población de 1993, lo cual representaba una pérdida poblacional promedio anual de 430000 personas. Incluso hay estudios serios, como uno de Naciones Unidas ${ }^{43}$ que plantea escenarios en los cuales, de continuar las tendencias de baja fertilidad y alta mortalidad, la población rusa podría descender a 125-135 millones para 2025 y a 100 millones para 2050.

Rybakovskii considera que la explicación del alza en las tasas de mortalidad en la Federación Rusa y el declive en la expectativa de vida es antes que nada sistémica. ${ }^{44}$ El empeoramiento en la salud y la tasa creciente de mortalidad han sido causadas por el colapso del sistema de salud y sanidad. Lodahl, por su parte, destaca la diseminación epidémica de las enfermedades de transmisión sexual después del colapso de la URSS. ${ }^{45}$ Lo que Lodahl concluye

${ }^{40}$ Ibid.

${ }^{41}$ Esto también es advertido por Maria Lodahl (art. cit.), al señalar que, generalmente hablando, los grupos étnicos no eslavos exhiben tasas más altas de nacimiento. En 1999, según Lodahl, eran Daguestán e Ingushetia las únicas dos (entre 89 regiones) que tenían una tasa de natalidad suficiente para mantener su población.

42 Leonid Rybakovskii, "The Demographic Development of Russia and Its Dominance in the First Quarter of the Twenty-First Century", Sociological Research, vol. 51, núm. 5, septiembre-octubre de 2012, p. 64.

${ }^{43}$ United Nations, Demographic Policy in Russia: From Reflection to Action, Moscú, United Nations in Russia, 2008.

${ }^{44}$ Leonid Rybakovskii, "Russian Population Dynamics and Its Components in 2001-25”, Russian Social Science Review, vol. 54, núm. 4, julio-agosto de 2013, pp. 50-62.

${ }^{45}$ Lodahl, art. cit. 
es que las discontinuidades en la conducta reproductiva y en otros ámbitos de vida en la Federación Rusa están asociados con los cambios políticos y sociales que implicó la transición de una economía centralmente planificada hacia una de mercado. Tom Parfitt agrega que algunas de las causas de muerte en la Federación Rusa (alcoholismo, tuberculosis, VIH-SIDA, accidentes carreteros, suicidios) no son naturales pero sí erosionan la población a tasas alarmantes. ${ }^{46}$ Otros factores que dan cuenta de la singular crisis demográfica, según Rybakovskii, ${ }^{47}$ son la falta de acceso de una porción considerable de la población al descanso apropiado y el ocio, la falta de cuidado en las normas de protección laboral y las regulaciones de seguridad, así como el estrés, el empeoramiento del crimen y un uso creciente de narcóticos, además de un importante crecimiento en la tasa de suicidios. ${ }^{48}$

Fue apenas en la segunda mitad de la primera década del siglo xxi que se dio una mejoría sistemática en la situación demográfica rusa (aunque este avance es insuficiente afirma Rybakovskii). No obstante presentarse una "mejoría”, el mismo autor advierte que todos los indicadores demográficos rusos son significativamente peores que los de la década de $1980 .{ }^{49}$ La mejoría coincide con la implementación de una política demográfica activa en 2006-2010. No obstante lo anterior, dadas las tasas actuales de mortalidad y nacimiento, los niños sólo pueden reemplazar a sus padres en un $74 \%$ (en 2005 la cifra era de 60\%)..$^{50}$ En 2009, por primera vez en 17 años, el tamaño de la población del país no declinó, en parte como resultado de que la migración compensó la pérdida natural de población. ${ }^{51}$ Lo mismo sucedió en 2010.

${ }^{46}$ Tom Parfitt, "Russia's Population Crisis", The Lancet, vol. 365, 26 de febrero de 2005, pp. 743-744.

${ }^{47}$ Rybakovskii, "Russian Population Dynamics and Its Components in 2001-25".

48 Comparado con 1991 los suicidios en 1994 subieron un $57.4 \%$ por cada 100000 habitantes y en el caso de hombres en zonas rurales un 73.6\%. Véase Leonid Rybakovskii, "Russian Population Dynamics and Its Components in 2001-25", p. 51 .
${ }^{49}$ Ibid., p. 52.
${ }^{50}$ Loc. cit.
51 Ibid., p. 54. 
Hay cuatro problemas demográficos sistémicos para la Federación Rusa: el menor número de mujeres en edad reproductiva, la edad creciente para que la mujer tenga su primer hijo (25.8 años en 2000 y 27.4 años en 2009), el porcentaje creciente de la población anciana ${ }^{52}$ y el declive en el potencial migratorio de los países en el cercano extranjero. Esto, según Rybakovskii, hará que "Rusia al final encare una situación demográfica extremadamente difícil". ${ }^{53}$

Con particular importancia dentro de los cuatro problemas sistémicos mencionados en el párrafo anterior, y para los fines de este artículo, está el hecho de que los países que resultaron del espacio postsoviético muestran un declive sustancial en su potencial migratorio hacia la Federación Rusa. Rybakovskii estima que de los 25.3 millones de personas de filiación rusa que habitan allende sus fronteras, el potencial migratorio no excede de los cinco millones. La migración anual debería ser de entre 350000 y 400000 personas, comparada con la actual de 250000.54

Como puede verse, la cuestión migratoria es un punto nodal para la Federación Rusa. Lodahl considera que no es necesariamente la cantidad reducida de migrantes el problema, sino que muchos de los rusos (que habitan en la Federación Rusa) o de los rusos étnicos (que viven más allá de las fronteras de la Federación Rusa) han decidido emigrar al resto del mundo, sobre todo desde 1987, cuando las nuevas leyes lo permitieron. ${ }^{55}$ Esto representa una sangría de población altamente educada, de trabajadores cualificados y en general de capital humano. Lodahl contrasta la calidad de la gente que emigra al resto del mundo con la que entra a la Federación Rusa, y considera que los que entran al país tienen menor calidad. La concepción de política migratoria para 2025 reconoce la reubicación de migrantes permanentes como una de

52 Según datos correspondientes a 1999, en ese año, por primera vez, el número de ancianos en la Federación Rusa, excedió al número de niños menores de quince años, véase María Lodahl, art. cit., p. 261.

${ }^{53}$ Rybakovskii, "The Demographic Development of Russia and Its Dominance in the First Quarter of the Twenty-First Century", p. 71.

${ }^{54}$ Rybakovskii, "Russian Population Dynamics and Its Components in 2001-25”.

${ }^{55}$ Lodahl, art. cit. 
las fuentes de crecimiento del país y como una de las necesidades para el desarrollo continuo del mismo. ${ }^{56}$

Dos importantes políticas ponen de manifiesto la importancia que el Estado ruso da a la situación demográfica del país: la primera es la Concepción de Política Demográfica, aprobada por decreto presidencial en octubre de 2007. Entre sus objetivos está: a) para 2015, incrementar la población a unos 142-143 millones; $b$ ) incrementar la población a 145 millones para 2025; c) aumentar la expectativa de vida a 70 años para 2015; y $d$ ) incrementar la expectativa de vida a 75 años para $2025 .{ }^{57}$ La segunda política que retoma el problema demográfico es el Concept for the Russian Federation's State Policy on Migration up to 2025, aprobada por el presidente en junio de 2012. Dicha política tiene entre otros objetivos: fortalecer la seguridad nacional del país; estabilizar e incrementar el tamaño de la población permanente de la Federación Rusa; y ayudar a su economía en las necesidades actuales y futuras de fuerza laboral, modernización, desarrollo innovador y alta competencia. Entre las tareas estatales, dicho concepto incluye la creación de condiciones e incentivos para la reubicación permanente hacia la Federación Rusa de compatriotas en el extranjero. Llama también a implementar el National Program for Supporting Voluntary Migration of the Compatriots Residing Abroad to the Russian Federation, mismo que fue aprobado en 2006 y lanzado en 2007.

Respecto a la preocupación migratoria, Rybakovskii concluye que la escala de la migración potencial hacia la Federación Rusa será menor cada año que pasa y considera dicha disminución desde los países que alguna vez integraron la URSS, ocurrida en los veinte años posteriores al colapso de la URSS, como un grave problema para la Federación Rusa. ${ }^{58}$ Rybakovskii estima que la migración potencial de rusos étnicos en el Cercano Extranjero no excede los cinco millones. Por ejemplo, en un comparativo de 2009 y 2010,

${ }^{56}$ Federal Migration Service of the Russian Federation, Concept for the Russian Federation's State Policy on Migration up to 2025, 13 de junio de 2012.

${ }^{57}$ United Nations, Demographic Policy in Russia: From Reflection to Action, Moscú, United Nations in Russia, 2008.

${ }^{58}$ Rybakovskii, "The Demographic Development of Russia and Its Dominance in the First Quarter of the Twenty-First Century". 
Katarzyna Jarzynska, basándose en cifras oficiales, ilustra cómo entre los catorce Estados que componen el Cercano Extranjero ruso, sólo dos -Estonia y Letonia- muestran un incremento en la tasa migratoria neta hacia la Federación Rusa. ${ }^{59}$ Lituania permanece igual, mientras que la tasa de migración neta hacia la Federación Rusa desciende en los otros once Estados.

Rybakosvkii apunta que desde 2007 se tomó una serie de medidas estatales como impulsar el tener un segundo y tercer hijo, reducir la edad del matrimonio, apremiar el nacimiento del primer hijo, beneficios en pensiones, etc. ${ }^{60}$ Sin embargo, prácticamente cualquier estudio serio en materia demográfica considera que las políticas, que ciertamente han logrado detener la sangría poblacional, resultan insuficientes en el mediano y largo plazo. Por lo anterior, es que en este estudio se considera que la administración de Putin ha visto en la anexión de Crimea una solución más duradera, aunque quizá no excluyente de las políticas convencionales de estimulación demográfica.

Aunque la crisis poblacional tiene efectos en prácticamente cualquier rubro de la economía y la sociedad, Rybakovskii se pregunta, literalmente, si el país (su integridad territorial) podrá sobrevivir sin gente. Y su respuesta es: es poco probable. Dadas las actuales condiciones demográficas, sobre todo en la zona asiática, no puede instalarse un ejército competitivo, no puede florecer industria, ni haber una hacienda fuerte, mucho menos un mercado doméstico que detone futuras actividades económicas si no logra antes revertirse los patrones demográficos adversos, incluso después de la "mejoría" post-2007. Aunque, en los últimos años, la expectativa de vida al nacer ha mejorado, lejos se está de revertir las tendencias decrecientes de la población de las últimas dos décadas; por ejemplo, para el periodo enero-abril de 2014, el número de decesos excedió en $4.6 \%$ al número de nacimientos. Sin embargo, después de la anexión de Crimea, la población de la Federación

${ }^{59}$ Katarzyna Jarzynska, "A New Concept of Migration Policy in Russia”, 20 de junio de 2012, Osrodek Studiow Wschodnich (sitio electrónico), http://www.osw. waw.pl/en/publikacje/analyses/2012-06-20/a-new-concept-migration-policy-russia

${ }^{60}$ Rybakovskii, documentos citados. 
Rusa creció hasta alcanzar 146 millones de personas, gracias a la incorporación de 2.3 millones de habitantes en Crimea. ${ }^{61} \mathrm{Si}$ se observa que los cálculos para 2025, de acuerdo con el Servicio Federal de Migración, ${ }^{62}$ fluctuaba entre los 142.8 millones y los 145.6 millones de personas, es claro que la anexión de Crimea es consistente con las metas estatales.

El problema migratorio, por su parte, no es meramente un asunto cuantitativo. La cuestión nacional, que empieza, aunque no se limita, en lo lingüístico, plantea el problema adicional de que la Federación Rusa no sólo requiere migrantes, sino que requiere que éstos tengan ciertas competencias lingüísticas para poder integrarse sin mayores dificultades a la sociedad rusa, en la que deben estudiar o trabajar. Adicionalmente, está el problema étnico, aunque no se lo abordará dentro del presente artículo. El análisis se limita al problema lingüístico. En Ucrania, por ejemplo, los líderes ultranacionalistas que depusieron a Viktor Yanukovich, repudiaron la ley de 2012 que permitía que el ruso y otras lenguas minoritarias fueran usadas localmente. ${ }^{63}$ En un sentido contrario tenemos a Bielorrusia, Estado que no obstante tener una mala reputación internacional, bajo Lukashenko (presumiblemente un dictador), en 2009 prometió mantener la paridad entre las lenguas bielorrusa y la rusa. Lukashenko se apegó a los resultados del referéndum y reconoció que "la discusión sobre la lengua en el país no beneficiaba a nadie" ${ }^{64}$

${ }^{61}$ Interfax, "As of May 1 Russian population reaches $146 \mathrm{mln}, 2.3 \mathrm{mln}$ of them in Crimea-Rosstat”, 20 de junio de 2014, en EBSCO Host, http:/ /web.a.ebscohost. $\mathrm{com} /$ ehost $/$ detail $/$ detail?vid $=7 \&$ sid $=642799 \mathrm{ba}-8284-428 \mathrm{~b}-8 \mathrm{f0} 0 \mathrm{f} 3 \mathrm{c} 580903 \mathrm{e} 51 \% 40 \mathrm{~s}$ essionmgr4002\&hid=4212\&bdata=Jmxhbmc9ZXMmc210ZT1laG9zdC1saXZl\#db= bwh\&AN=96689895 (consultado el 27 de noviembre de 2014).

${ }^{62}$ Federal Migration Service of the Russian Federation, Concept for the Russian Federation's State Policy on Migration up to 2025, 13 de junio de 2012.

63 "Time for Realism and Common Sense on Ukraine", The Nation, 24 de marzo de 2014.

${ }^{64}$ Interfax, "Parity between Belarusian, Russian Language to Be Preserved in Belarus-Lukahenko", Russian E CIS Presidential Bulletin, 31 de diciembre de 2009, en EBSCOHost http:/ / web.a.ebscohost.com/ehost/detail/detail?vid=9\&sid=6427 99ba-8284-428b-8f08-f3c580903e51\%40sessionmgr4002\&hid=4212\&bdata=Jmxhb mc9ZXMmc210ZT1laG9zdC1saXZl\#d b=bwh\&AN=48527835 (consultado el 26 de noviembre de 2014). 
El problema de la lengua rusa no debe ser visto como algo menor dentro del enfoque del realismo demográfico. ${ }^{65}$ Esto es importante sobre todo si se atiende el hecho de que durante los últimos años del imperio soviético, el ruso tenía un papel dominante dentro de la URSS y, como señala William Fierman, "en una amplia gama de dominios, el ruso había desplazado a las lenguas titulares de muchas minorías soviéticas". ${ }^{66}$ Fierman observa que, quizá con la excepción de Bielorrusia, el perfil del idioma ruso dentro del espacio post-soviético es mucho menor que al momento del colapso de la URSS. El rol del ruso era especialmente importante en el Asia Central a diferencia de lo que pasaba en las repúblicas bálticas y en el sur del Cáucaso. El papel del ruso era tan importante que Fierman destaca que según datos del censo, en 1990, "no obstante más de $98 \%$ de la población kazaja y kirguisa consideraban al kazajo y al kirguís como su lengua nativa, muchos de ellos, especialmente en áreas urbanas, tenían un dominio muy limitado de dichas lenguas". ${ }^{67}$ El estatus oficial del ruso sólo es otorgado en tres de los países de la ex URSS: Bielorrusia, Kazajistán ${ }^{68}$ y Kirguistán. ${ }^{69}$ En la actualidad, mientras que el ruso es una lengua oficial a la par del kazajo, ha desaparecido virtualmente como lengua de uso en los órganos legislativos y las oficinas de gobierno en el Báltico y en el sur del Cáucaso. ${ }^{70}$ Clifford Levy ejemplifica la situación lingüística

${ }^{65}$ Es importante mencionar que en este artículo se usa la idea del "realismo demográfico" no como una teoría nueva, ni como un competidor del realismo de naturaleza humana, realismo defensivo o la variable del realismo ofensivo. La idea es simplemente devolver el énfasis, no siempre claro, que la escuela realista pone o debería de poner en la población como un componente central del poder estatal.

${ }^{66}$ William Fierman, "Russian in Post-Soviet Central Asia: A Comparison with the States of the Baltic and South Caucasus", Europe-Asia Studies, vol. 64, núm. 6, agosto de 2012, p. 1077.

67 Ibid., p. 1082.

68 Tanto Bielorrusia como Kazajistán son signatarios de la Unión Económica Euroasiática.

${ }^{69}$ Sergei Gradirovski y Neli Esipova, "Russian Language Enjoying a Boost in post-Soviet States", Gallup Poll Briefing, 1 de agosto de 2008, en http:/ /www.gallup. com/poll/109228/russian-language-enjoying-boost-postsoviet-states.aspx (consultado el 30 de noviembre de 2014).

${ }^{70}$ Fierman, art. cit. 
prevaleciente en el Cáucaso. Levy observa que existe "una brigada de nativos anglófonos reclutados por el gobierno de Georgia para propiciar una revolución lingüística". ${ }^{71}$ De acuerdo con Levy, "El objetivo es hacer de Georgia un país en el que el inglés sea tan común como lo es en Suecia, y en el proceso, reemplazar al ruso como la segunda lengua dominante". ${ }^{72}$ Las políticas tienen como objetivo que toda escuela del país tenga por lo menos un anglófono nativo. Para Levy, esta competencia lingüística va más allá de la comunicación, tratándose para los rusos, según su opinión, del estatus de la lengua rusa como una suerte de barómetro de su influencia.

Un dato que alarma a las autoridades migratorias rusas es el reporte del Servicio Federal de Migración, según el cual hasta $80 \%$ de los migrantes menores de 30 años no hablan ruso. ${ }^{73}$ Esto entra en conflicto con una ley que requiere que los trabajadores extranjeros que laboren o planeen desempeñarse en servicios públicos, comercio y servicios deben validar su conocimiento de ruso desde el 1 de diciembre de 2012. Esto incluye a los ciudadanos extranjeros de países que no requieren visado ruso.

En el ciclo escolar 2001-2002, por ejemplo, en el Caúcaso, la situación es muy diferente a la del Asia Central, en donde el ruso es materia obligatoria y las clases en ruso son comunes en Kazajistán y Kirguistán. Aun cuando los niños estudien en su lengua nacional, muchos materiales están disponibles sólo en ruso. ${ }^{74}$

Algo que debería de preocupar a los líderes rusos, al menos desde el enfoque planteado, de realismo demográfico, es que a la par de la emigración, el cambio en la composición étnica del Asia

71 Clifford J. Levy, "Still Fighting Russia, this Time with Words", The New York Times, 23 de enero de 2011, en http://www.nytimes.com/2011/01/24/world/ europe/24georgia.html?_r=0 (consultado el 5 de mayo de 2015).

72 Loc. cit.

${ }^{73}$ Interfax, "Up to $80 \%$ of labor migrants do not know Russian language- Federal Migration Service”, Russia E CIS Business Eं Financial Newswire, 24 de diciembre de 2012, en EBSCO Host, http://web.a.ebscohost.com/ehost/detail/detail? vid=12\&sid=642799ba-8284-428b-8f08f3c580903e51\%40sessionmgr4002\&hid $=42$ 12\&bdata=Jmxhbmc9ZXMmc210ZT1laG9zdC1 saXZl\#db=bwh\&AN=84458877 (consultado el 28 de noviembre de 2014).

${ }^{74}$ Fierman, art. cit. 
Central ha sido moldeada por tasas más altas de natalidad entre los miembros nacionales titulares que entre los eslavos. ${ }^{75}$ Esto es relevante, ya que, como señala Eberstadt, la migración, principalmente la de los Estados anteriormente soviéticos, ha amortiguado la crisis poblacional, pero no la ha solucionado. ${ }^{76}$ De hecho, la Federación Rusa ocupa el segundo lugar mundial con 11 millones de migrantes que habitan en ella, lo cual ubica al país sólo por debajo de Estados Unidos, como receptor de migrantes. ${ }^{77} \mathrm{El}$ problema con la perspectiva de la migración no es tanto cuantitativa como cualitativa, toda vez que la política educativa en el espacio postsoviético tiende a la des-rusificación, lo cual se traduce en que los inmigrantes del Cáucaso y del Asia Central hablan menos ruso que sus padres, lo cual dificulta su integración a la sociedad rusa. No obstante ocupar el segundo lugar entre los países receptores de migrantes, la Federación Rusa ha tenido un ligero descenso como país captador de migrantes en la primera década del siglo xxi (de 12 millones en 2000 pasó a 11 millones una década después). Otro problema es que, a diferencia de Europa y según reportes del Servicio Migratorio Federal Ruso, sólo un porcentaje menor de los migrantes internacionales se ha establecido temporalmente (como residente temporal) o permanentemente en la Federación Rusa (718600 personas). ${ }^{78} \mathrm{Al}$ respecto, Olga Kirilova, jefa del Servicio de Migración de Moscú, comenta: "Es muy molesto que los representantes de la región de Asia Central vengan en números crecientes año con año, pero que hablen menos ruso [...] El tiempo cuando todos estábamos en el mismo país y las escuelas enseñaban ruso de manera obligatoria e historia común se está desvaneciendo". ${ }^{79}$

75 Ibid., p. 1089.

${ }^{76}$ Eberstadt, art. cit.

77 Andrei Stenin, "Russia Has World's $2^{\text {nd }}$ Largest Number of Immigrants-UN Study", Sputnik News (online), 12 de septiembre de 2013, en http:/ /sputniknews. com/russia/20130912/183384782.html (consultado el 29 de noviembre de 2014).

${ }^{78}$ Andrei Stenin, "Russia Has World's $2^{\text {nd }}$ Largest Number of Immigrants-UN Study”, Sputnik News (online), 12 de septiembre de 2013, en http:/ /sputniknews. com/russia/20130912/183384782.html (consultado el 29 de noviembre de 2014).

79 Interfax, "Russian Language Skills of Migrant Workers from Central Asia Getting Worse, Moscow Migration Service”, 11 de abril de 2013, en EBSCO Host, 
Paralelo a esta realidad, la actitud de la población rusa es más hostil hacia los recién inmigrados de estas regiones. ${ }^{80}$

Para concluir el presente apartado, es preciso reconocer que hay realidades que ni la migración ni los cambios fronterizos pueden solucionar, como lo son la mortalidad, la expectativa de vida al nacer. Esto es algo que el Estado ruso, más allá de su realismo demográfico, tendrá que entender y mejorar, si pretende sacar provecho a las medidas derivadas de su actuación en Crimea. Es incuestionable que el Estado ruso, por problemas y limitantes internas, no ha logrado mejorar la calidad de vida de su población en muchos sentidos. Por ejemplo, para 2009, la expectativa de vida a los 15 años era más baja que en países como Bangladesh, Timor Oriental, Eritrea, Madagascar, Níger y Yemen. En el caso de los adultos varones, la expectativa de vida era menor a países como Sudán, Ruanda y Botsuana. ${ }^{81}$ Sin embargo, si el Estado logra mejorar las condiciones de vida de su población, el recurso a las acciones emprendidas bajo esta visión de realismo demográfico puede ser benéfico para la Federación Rusa.

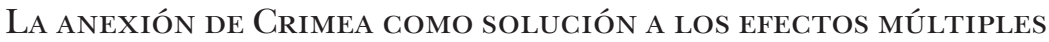 DE LA CRISIS POBLACIONAL}

A lo largo del presente artículo se argumenta que la explicación demográfica de la anexión de Crimea no debe ser descartada; después de todo, sería difícil de entender al margen de esta explicación por qué el primer ministro ruso, Dmitri Medvédev, ordenó un censo de población en el Distrito Federal de Crimea y Sevastopol para el cuarto trimestre de $2014 .^{82}$ Si la anexión fuese una

\footnotetext{
http:/ / web.a.ebscohost.com/ehost/detail/detail?vid=18\&sid=642799ba-8284428b- 8f08f3c580903e51\%40sessionmgr4002\&hid=4212\&bdata=Jmxhbmc9ZXM mc210ZT1laG9 zdC1saXZl\#db=bwh\&AN=86946220 (consultado el 30 de noviembre de 2014).

${ }^{80}$ Nicholas Eberstadt, art. cit.

81 Ibid., pp. 97-98.

${ }^{82}$ Para diciembre de 2014, dicho censo reportó una población de 2.28 millones de personas en Crimea. Véase Krymedia, "Results of Census: Population of
} 
simple estrategia para evitar el encirclement occidental, o para confirmar el rechazo ruso de las pretensiones de un orden internacional monopolar, el censo ordenado, como una de las primeras medidas del Estado ruso sobre el territorio recién anexado, no tendría mayor lógica. En este apartado se explica cómo la lógica demográfica de la anexión de Crimea da respuesta a múltiples cuellos de botella, entre ellos: militares, preocupaciones migratorias, ampliación del mercado doméstico y regional, incremento de la base fiscal, zonas de experimentación para atracción de inversiones, y, al igual que Osetia del Sur y Abjasia, como reserva territorial (que puede ser poco significativa para el gigantesco país), pero sobre todo permite contar con una reserva poblacional.

En cuanto a los cuellos de botella militares, Kathrin Hille destaca la importancia del puerto de Sevastopol para el poderío naval ruso en el Mediterráneo y más allá: "La base es de una importancia crítica en la medida que Rusia busca recuperar algo de su influencia global, que ha sido menguada desde la desintegración del imperio soviético". ${ }^{83}$ La misma Hille observa: "El significado de la base fue resaltado durante la guerra de 2008 con Georgia, cuando la flota rusa participó en bloqueos en el mar Negro y fue usada para lanzar aterrizajes anfibios. También ha probado su utilidad para Rusia durante la crisis libia, las misiones antipiratería en el Océano Índico y el rol de Moscú en el desmantelamiento de las armas químicas sirias". ${ }^{84}$

Lo anterior, respecto al valor estratégico per se. Ahora, dentro de las consideraciones del realismo demográfico ruso, una limitante para la Federación Rusa es que bajo un acuerdo con Ucrania, se limitaba a $25000 \mathrm{el}$ personal estacionado en la región. ${ }^{85} \mathrm{El}$ hecho de que la base esté hoy ya inscrita dentro de la jurisdicción

Crimea Is 2.284 Million People”, 16 de diciembre de 2014, en http:/ /en.krymedia.ru/society/3365334-Results-of-Census-Population-of-Crimea-is-2284-MillionPeople (consultado el 4 de mayo de 2015).

${ }^{83}$ Citada en Robert Orr, "Why Crimea Matters to Russia”, Blog, 3 de marzo de 2014, en http://blogs.ft.com/the-world/2014/03/why-crimea-matters-to-russia/ (consultado el 30 de noviembre de 2014).

${ }^{84}$ Loc. cit.

${ }^{85}$ Loc. cit. 
rusa elimina de tajo el problema. Hoy, ya no sólo deja de ser una preocupación el límite de las 25000 personas, sino que existen más de dos millones de personas potencialmente disponibles, en el presente o en el futuro, para trabajar en el sector militar o en otros sectores de la economía. Incluso, puede haber un excedente poblacional dispuesto a reubicarse a otras regiones rusas, en caso de que existan los incentivos para hacerlo.

Otra limitante era el no poder contar con nuevos barcos ni poder mejorar los ya existentes. ${ }^{86}$ Orr magnifica la importancia de Sevastopol al observar que la Federación Rusa ya no puede usar la base naval de Tartús en Siria como resultado de la guerra civil. Aunque el arrendamiento de Sevastopol se extendía hasta 2042, los eventos cambiantes en el mundo preocupaban de manera creciente a la Federación Rusa. ${ }^{87}$ La importancia militar de Crimea se ve en el plan de Moscú de inyectar casi 3000 millones de dólares en la modernización de la infraestructura militar de la época soviética. ${ }^{88} \mathrm{El}$ ministro de defensa ruso, Sergei Shoigu prometió canalizar 2800 millones de dólares para mejorar la Flota del Mar Negro y los campos aéreos, los puertos y las barracas militares. La idea es que los campos aéreos en Crimea puedan alojar bombarderos de largo alcance para 2016. También alojará barcos de guerra Mistral comprados a Francia. Crimea es clave para la proyección de poder ruso no sólo en el Mar Negro sino en el Mediterráneo, así como para proteger líneas comerciales vitales y los gasoductos. Andrzej Wilk también habla sobre los cambios militares que traerá la anexión de Crimea: ${ }^{89}$ además del evidente incremento de las fuerzas armadas

${ }^{86}$ Lukas Alpert, "Russia Steps Up Military Plan in Crimea", The Wall Street Journal, 26 de marzo de 2014, en http:/ /www.wsj.com/articles/SB1000142405270 2304679404579461532858444564

${ }^{87}$ Paul Schwartz, "Crimea's Strategic Value to Russia”, 18 de marzo de 2014, Center for Strategic \& International Studie, en http:/ / csis.org/blog/crimeas-strategic-value-russia (consultado el 30 de noviembre de 2014).

88 Alpert, art. cit.

89 Andrzej Wilk, "The Military Consequences of the Annexation of Crimea", Osrodek Studiów Wschodnich, 19 de marzo de 2014, véase http://www.osw.waw. $\mathrm{pl}$ /en/publikacje/analyses/2014-03-19/military-consequences-annexation-crimea (consultado el 5 de noviembre de 2014). 
rusas y de la modernización de la Flota del Mar Negro, habrá ahorros cuantificables para el Ministerio de Defensa Ruso al no tener que pagar más rentas por la base. Para Ucrania podría representar la eliminación completa de su flota en el Mar Negro, lo cual disminuye su capacidad de resistencia en caso de un futuro conflicto militar entre ambos países. En el ámbito regional, podría significar la superación de la flota turca en el Mar Negro y, más aún, para finales de la década actual la Federación Rusa podría gozar de una ventaja sobre el combinado de maniobra de todos los miembros de la otan en el Mar Negro.

En cuanto a los cuellos de botella migratorios, éstos se han abordado con cierto detalle en el apartado anterior. Basta decir ahora que al respecto Crimea tiene una doble función: compensar los déficits migratorios rusos y posibilitar que los "nuevos arribos" a la Federación Rusa tengan las calificaciones lingüísticas que los migrantes de otras regiones del espacio anteriormente soviético han comenzado a perder.

Un cuello de botella adicional que ayuda a superar la anexión de Crimea, por lo menos potencialmente, es el de un mercado nacional que se ha visto reducido por la pérdida de población durante las últimas dos décadas. La incorporación de 2.28 millones de habitantes a la Federación Rusa (tomando en cuenta el censo de finales de 2014) representa un incremento al mercado doméstico cercano a 2\%. Desde luego, la potencial ampliación del mercado tiene repercusiones en diversas esferas como la demanda, la extracción, la producción, la distribución y el consumo. Si al mercado doméstico agregamos el mercado regional que pretende significar la Unión Euroasiática, tenemos entonces que no sólo el mercado ruso, sino el de los miembros de dicha unión se ve robustecido.

La base tributaria representa otra preocupación indirecta entre los realistas, ya que, aunque generalmente se habla del crecimiento económico como un resorte clave del poderío estatal, una economía dinámica y productiva es un precondicionamiento para la construcción de un formidable poderío militar, una base tributaria confiable, de la cual el Estado pueda echar mano para la edificación, continuidad o profundización de programas militares, 
sólo es viable en un escenario de recaudación creciente. Aunque pueda argumentarse que, de inicio, la vinculación de Crimea con el resto de la Federación Rusa pueda representar una sangría de recursos, en el largo plazo es de esperarse que el territorio y la población de Crimea representen un núcleo fiscal adicional para el país. Al momento, dicho futuro parece lejano dadas las condiciones actuales que demandan la solidaridad del resto de la Federación Rusa para con la nueva entidad federativa. Es claro que no sólo en 2014, sino muy probablemente en los años venideros, la nivelación económica de Crimea, así como su integración física (por medio de la construcción de infraestructura que lo vincule al país) abren posibilidades de inversión, pero también de gastos antes de que la región pueda ser competitiva. Bajo esta lógica, en las semanas que siguieron a la anexión, Medvédev anunció planes para desarrollar un servicio de ferry, la construcción de un puente a lo largo del Estrecho de Kerch y quizá uno o dos puentes para trenes y otro para automóviles. ${ }^{90}$ Los esfuerzos para nivelar los índices de desarrollo de Crimea incluyen propuestas para la introducción de un "impuesto solidario" para que aquellos que ganan más de un millón de rublos (28 700 usD) al mes paguen, ya no $13 \%$ de su ingreso, sino $30 \%$, con el fin de apoyar y fortalecer los presupuestos regionales de los nuevos territorios de la Federación Rusa (propuesta del diputado Andrei Krutov). ${ }^{91}$ También se sugiere un incremento general de 1-2\% sobre el ISR (Impuesto sobre la Renta).

Las zonas económicas especiales (recordemos el caso de China) han probado ser importantes catalizadores de cambio y modernización económica en economías en transición. Una de las noticias que llama la atención es que Crimea será una zona económica especial, con incentivos fiscales para atraer a los inversionis-

90 TV-Novosti, "Crimea to Be a Special Economic Zone with Tax Breaks", 1 de abril de 2014, http:/ / rt.com/business/crimea-zone-tax-break-345/ (consultado el 25 de octubre de 2014).

${ }^{91}$ Cfr. Lidia Kelly, "Russia May Ask Rich to Help Foot Bill for Crimea with 'Solidarity Tax'”, Reuters, 22 de julio de 2014, http://www.reuters.com/article/2014/07/22/us- ukraine-crisis-russia-tax-idUSKBNOFR1SB20140722 (consultado el 1 de diciembre de 2014). 
tas, según comentó Dmitri Medvédev. La idea es que Crimea goce de un estatus similar al de otra de las zonas geográficamente separadas de la Federación Rusa -Kaliningrado- como zona económica especial. El problema que algunos ven en la legislación en desarrollo dentro del Ministerio de Desarrollo Económico es que pocos actores serían beneficiados con las condiciones de exención de impuestos sobre la propiedad, tierra, transportes e impuestos federales sobre ganancias, pues para calificar se exigen montos equivalentes a 4.3 millones de dólares, lo que dejaría fuera a los negocios pequeños y medianos. ${ }^{92}$ Para efectos de este artículo, lo que importa, más allá de las coyunturas específicas del momento, es visualizar los cuellos de botella existentes y las potenciales soluciones a éstos, en este caso, por medio del fortalecimiento demográfico de un Estado.

Es común hallar columnas de opinión y artículos académicos donde los autores cuestionan hasta dónde llegará el neo-expansionismo ruso. ${ }^{93}$ Es preciso reconocer que para 2014 existen aún otros lugares con importantes diásporas rusas los cuales incluyen a Estados del Báltico, particularmente a Letonia, país que tiene $26 \%$ de población étnica rusa. Esta reserva poblacional es sólo parte del problema. En el flanco sur-oriental, el país enfrenta presión en las zonas fronterizas densamente pobladas con China. ${ }^{94}$ Tom Parfitt observa el miedo que hay en la Federación Rusa de que vecinos muy poblados como China pudieran lentamente engullir el territorio ruso. ${ }^{95}$ La crisis de 2008 en Osetia del Sur y Abjasia, y el apoyo que el Estado ruso ha dado a su diáspora en el Cercano Extranjero, fortalecen una de las hipótesis que se presenta en este artículo: ambas repúblicas pueden representar una reserva territorial o poblacional en caso de que las circunstancias geoestratégicas o una nueva crisis demográfica se haga presente en la Federación

${ }^{92}$ Delphine D'Amora, "Tax Breaks May Not Be Enough to Jumpstart Crimea's Struggling Economy”, The Moscow Times, 29 de mayo de 2014, en http://www.themoscowtimes.com/business / article/tax-breaks-may-not-be-enough-to-jumpstartcrimeas-struggling-economy/501177.html (consultado el 1 de diciembre de 2014).

${ }^{93}$ Michael Crowley y Simon Shuster, art. cit.

${ }^{94}$ Nicholas Eberstadt, art. cit.

${ }^{95}$ Parfitt, art. cit. 
Rusa. Por lo anterior, Occidente debe tomar en cuenta, que el apoyo, hasta el momento de tipo autonómico, que la Federación Rusa ha brindado a ciertas regiones limítrofes puede convertirse, según las necesidades del momento, en una incorporación territorial/poblacional a ésta.

\section{LA UNIÓN EUROASIÁTICA COMO SOLUCIÓN NO-TERRITORIAL A LA CRISIS DEMOGRÁFICA RUSA}

Un artículo de Stratfor ayuda a entender la baja probabilidad de que la Federación Rusa continúe su expansión sobre el este ucraniano. ${ }^{96}$ No obstante los movimientos separatistas rusos que existen en ciudades como Donetsk, Khariv y Dnipropetrovsk, el análisis destaca las dificultades lógisticas que enfrentaría una ocupación militar similar a la de Crimea, dado que en el caso del último ya había una presencia militar estratégica en Sevastopol. Pero eso no es todo. Según el reporte, no está dentro del interés ruso separar al este del país del resto de Ucrania, pues se perdería en un futuro una importante palanca de negociación al darse una hipotética independencia o anexión a la Federación Rusa de las regiones ruso-parlantes del este. Bajo esta lógica, Moscú prefiere mantener los ímpetus, sean autonomistas, secesionistas o irredentistas como carta de negociación no sólo vis-à-vis Ucrania, sino vis-à-vis la UE y la oTAN. ${ }^{97}$ Ben Shapiro, por su parte, argumenta que si bien es difícil creer que Polonia y el resto de Ucrania puedan ser los siguientes puntos de agresión de parte de los rusos, tampoco resulta claro que sus ambiciones se detengan en Sevastopol. ${ }^{98}$ Shapiro conside-

${ }^{96}$ Stratfor, "Ukraine: Russia Looks Beyond Crimea", 3 de marzo de 2014, en EBSCO Host, http:/ / web.b.ebscohost.com/ehost/detail/detail?vid=4\&sid=2ec9df ea-a217-41dc-a60a0491 ebe60f26\%40sessionmgr112\&hid=105\&bdata=Jmxhbmc9Z XMmc210ZT1laG9zdC1saXZl\#db=bth\&AN=95421622 (consultado el 1 de diciembre de 2014).

${ }^{97}$ Loc. cit.

${ }^{98}$ Ben Shapiro, "Putin's Next 4 Targets", Breitbart (online), 18 de marzo de 2014, en http:/ /www.breitbart.com/national-security/2014/03/18/putin-four-invasions/ (consultado el 29 de noviembre de 2014). 
ra cuatro posibilidades de expansión territorial rusa: 1) la región del Trans-Dniester en Moldavia, misma que ha pedido en alguna ocasión a la Duma rusa redactar las leyes que permitan su unión a la Federación Rusa; 2) Georgia; 3) Kazajistán, Estado que tiene una gigantesca población étnica rusa; y 4) Bielorrusia, país que tiene $11 \%$ de población rusa y en donde el idioma ruso es lengua oficial a la par del bielorruso. Aunque no incluye como posibilidad real, destaca que Estonia (con 25.5\%), Letonia (con 27.6\%) y Lituania (con $5.8 \%$ ) tienen considerables porcentajes de población rusa.

Como bien señala Fierman, "El desarrollo de los futuros vínculos económicos entre el Asia Central y Rusia sin lugar a duda afectarán el lenguaje. En este aspecto, la Unión Económica Euroasiática (UEE) podría jugar un papel clave [...] Dependiendo del nivel real de integración, la UEE podría dar un impulso significativo al ruso en los Estados miembros". ${ }^{99}$ Esto es particularmente importante si atendemos las conclusiones de Fierman, quien destaca la serie de funciones que la lengua rusa sigue desempeñando en Asia Central a diferencia de las pérdidas de dicho idioma en el Báltico y en el sur del Cáucaso. La amenaza lingüística que representa la sustitución del ruso por el inglés no debe ser vista como asunto menor. Esto se torna especialmente relevante ante las políticas rusofóbicas en ambas regiones. En febrero de 2012, por ejemplo, los votantes en Letonia rechazaron de forma abrumadora una propuesta para adoptar el ruso como segunda lengua oficial, a pesar del porcentaje tan grande de rusos que habitan el país (26\%), de donde resulta que una de las minorías lingüísticas más numerosas del mundo (porcentualmente hablando) se vea afectada al ser el letón la única lengua estatal. Esto ha reducido sus derechos políticos, privando a muchos rusos de su derecho a votar en el referéndum en el cual se negó al ruso el estatus de segunda lengua oficial, con lo cual el malestar político puede llegar a gente que ha habitado en Letonia desde antes de que se desintegrara la URSS. Lituania y Estonia también han quitado énfasis al ruso desde $1991 .^{100}$

${ }^{99}$ Fierman, art. cit., p. 1096.

${ }^{100}$ David Herszenhorn, "Latvians Reject Russian as Second Language", The New York Times, 19 de febrero de 2012. 
Bielorrusia es otro de los Estados que ha sido tratado no sólo por diversos analistas, sino por los propios políticos de la región como un candidato a ser anexionado (incluso en su totalidad) a la Federación Rusa. Como producto del bajo acercamiento de Lukashenko con la UE y la resistencia al cambio y la democratización del dictador bielorruso, Uladzimir Dzenisevich advierte que la posibilidad de un respaldo occidental ante una eventual maniobra militar rusa es baja. ${ }^{101}$ Desde luego, considera que no se puede descartar más allá de cualquier afinidad de regímenes un apoyo europeo, anclado éste más bien en la lógica de contrabalancear a un "perpetrador". Al mismo tiempo, sostiene que los hechos demuestran una integración de facto de Bielorrusia con la Federación Rusa y no con la UE, lo cual hace vulnerable al país ante las decisiones de Moscú. Dzenisevich considera que la Federación Rusa ha sido clara, "Si la administración pro-rusa cae, Rusia no se apartará". ${ }^{102}$ La hipótesis de este artículo es que con la decisión de Bielorrusia de mantenerse dentro de la Unión Euroasiática después de la anexión de Crimea, no será necesario para la Federación Rusa la anexión territorial del país, dado que la unión permitirá contar con los beneficios de mercado, fuerza de trabajo y una base fiscal incrementada sin tener que asumir los costos políticos, militares y diplomáticos que la anexión bielorrusa representaría. Desde luego, la insistencia europea o noratlántica de atracción de esta importante parte del Cercano Extranjero ruso podría desembocar en la anexión como forma de evitar la pérdida de mercados, fuerza de trabajo y base fiscal.

Walt sugiere como posible solución a la crisis ruso-ucraniana que Estados Unidos restablezca la neutralidad ucraniana, lo cual en esencia significa que Ucrania sea un Estado amortiguador entre Este y Oeste, sin posibilidad de acceso a la otan, con posibilidades de cierta asociación con la uE pero sin ser parte de la esfera de influencia de la Federación Rusa. ${ }^{103}$ Es difícil evadir la pregunta:

101 Uladzimir Dzenisevich, "How the Annexation of Crimea Changed the Geopolitical Games for Belarus”, Beyond the EU (online), 25 de marzo de 2014, en http:/ /beyondthe.eu/crimea-russia-belarus/

102 Loc. cit.

103 Cfr. Philip Hamilton, "Professor Stephen Walt on the Crisis in Ukraine", Boston Global Forum, 25 de marzo de 2014. 
¿hasta qué punto el impedir que Ucrania forme parte de la esfera de influencia rusa logrará dar respuesta a la sensibilidad de seguridad rusa? Mearsheimer también propone como solución el convertir a Ucrania en un Estado amortiguador, fuera de las órbitas de influencia (occidental o rusa). ${ }^{104}$ Plantea que Occidente debe cesar en sus esfuerzos por occidentalizar al país, de incorporarlo a la oTAN y probablemente a la uE. También debe cesar en su patrocinio de las revoluciones de colores y, de hecho, debe promover los derechos lingüísticos de las minorías, especialmente los derechos lingüísticos de los ruso-parlantes.

El futuro de la Unión Económica Euroasiática, se argumenta en este artículo, será el factor determinante del cual depende la contención o la ulterior expansión territorial rusa. Dicha Unión entró en vigor en enero de 2015 y reducirá barreras comerciales y migratorias a más de 170 millones de personas dentro del espacio post-soviético. ${ }^{105}$ La Unión garantizará el libre tránsito de bienes, servicios, capital y trabajadores. ${ }^{106}$ Actualmente, tanto Bielorrusia como Kazajistán están en el tercer puesto como socios comerciales de la Federación Rusa, sólo detrás de la ue y de China. Se especulaba sobre la potencial adhesión de Armenia (hay que hacer notar que desde enero de 2015 ya es miembro de pleno derecho), Tayikistán y Kirguistán. Azerbaiyán se debate entre la Unión Económica Euroasiática y la Unión Europea. En caso de que dicha Unión sea exitosa y que logre cumplir con sus fines, la Federación Rusa habrá de solucionar varias de sus preocupaciones demográficas, directa e indirectamente. Al contrario, si Occidente insiste en hacer "sangrar" a la Federación Rusa como consecuencia de la anexión de Crimea, sobre todo apostando al fracaso de una Unión Económica Euroasiática, entonces se puede vaticinar que Crimea será sólo el primero de una serie de territorios/poblaciones en ser anexionados por una Federación Rusa resurgente.

${ }^{104}$ Mearsheimer, "Why the Ukraine Crisis Is the West's Fault".

105 TV-Novosti, "Russia, Belarus, Kazakhstan sign 'epoch' Eurasian Economic Union”, 29 de mayo de 2014, véase http://rt.com/business/162200-russia-bealrus-kazakhstan-union/ (consultado el 25 de octubre de 2014).

106 Barbara Tasch, "Russia, Kazahstan, Belarus Sign Treaty Creating Huge Economic Bloc”, 30 de mayo de 2014. 


\section{CONCLUSIONES}

El presente artículo, sin descartar las explicaciones convencionales de la anexión de Crimea por parte de la Federación Rusa, ha agregado una nueva explicación, la del "realismo demográfico". Del presente análisis, se puede apreciar la existencia de diversos documentos oficiales, así como pronunciamientos oficiales durante los últimos quince años, mismos que le otorgan a la cuestión demográfica un papel central dentro de la seguridad nacional rusa.

Mientras la gran mayoría de los países europeos se prepara, y de alguna manera conforme aceptan la realidad de que enfrentarán un descenso demográfico (así lo sugieren diversas proyecciones oficiales), para la Federación Rusa, país que busca recuperar o mantener su estatus de gran potencia regional, la pérdida de población parece causar una mayor alarma que entre el resto de los países del continente. Adicionalmente, la enorme frontera de la Federación Rusa con China despierta el temor del desbalance demográfico existente entre ambos países. Otro factor que permite entender la especial preocupación rusa respecto al tamaño de su población es el hecho de que su economía, con menor diversificación y con menor productividad que las economías europeas, aún depende en gran medida de la extracción de los recursos naturales, actividad que requiere del uso extensivo de mano de obra.

Del análisis presentado se puede hipotetizar que Occidente jugará un rol central dentro de las decisiones futuras en la política exterior de la Federación Rusa: si Occidente ve a la Federación Rusa como una potencia par, y logra entender la legitimidad de las preocupaciones rusas, entonces se habrá dado un paso importante para que la Federación Rusa pueda atender sus intereses vitales por medio de la edificación y fortalecimiento de instituciones comerciales, como la Unión Económica Euroasiática. En caso contrario, si Occidente apuesta al fracaso de dicha Unión, la Federación Rusa habrá de echar mano de la expansión territorial y del engullimiento poblacional. Estas medidas seguramente irritarán a los líderes en Occidente, lo que conducirá a nuevas rondas de sanciones económicas hacia la Federación Rusa. Será entonces difícil poner un fin a la expansión territorial rusa. 
Como resultado del análisis aquí presentado, se sugiere una política de "verdadero" reset, anclado en una responsabilidad compartida para atender y dar solución, por un lado, a la crisis demográfica rusa; por otro lado, para frenar el expansionismo ruso. La cooperación, no sólo de Occidente, sino también de China, para generar inversión y desarrollo en las áreas fronterizas rusas con poca población, podría mitigar las preocupaciones legítimas que la Federación Rusa pueda tener respecto a la integridad territorial del Estado. Por otra parte, en la medida en que se ayude a que la Federación Rusa transite hacia una economía con mayor productividad, mayor valor agregado y menor dependencia del sector extractivo, podría promoverse que la Federación Rusa, como sucede con varios países de Europa, perciba "su debilidad" demográfica como un factor positivo (ventajas que ciertamente da el contar con una población limitada) y no como una amenaza para la supervivencia del Estado. Por lo que concierne a la política, es importante que Occidente cese en su patrocinio y respaldo a movimientos nacionalistas en el espacio postsoviético, que tanto daño han ocasionado a los ruso-parlantes y que, en lugar de fomentar una zona creciente de paz, han alimentado, por las razones explicadas, el expansionismo ruso.

\section{BibLIOGRAFÍA}

Alpert, Lukas, "Russia Steps Up Military Plan in Crimea”, The Wall Street Journal, 26 de marzo de 2014, en http://www.wsj.com/articles/SB10 001424052702304679404579461532858444564

Crowley, Michael y Simon Shuster, "This Is War", Time, 19 de mayo de 2014, pp. 31-35.

D’Amora, Delphine, "Tax Breaks May Not Be Enough to Jumpstart Crimea's Struggling Economy", The Moscow Times, 29 de mayo de 2014, en http://www.themoscowtimes.com/business/article/tax-bre aks-may-not-be-enough-to-jumpstart-crimeas-struggling-economy/ 501177.html

Dawisha, Karen, Putin's Kleptocracy: Who Owns Russia, Nueva York, Simon \& Schuster, 2014. 
Dzenisevich, Uladzimir, "How the Annexation of Crimea Changed the Geopolitical Games for Belarus", Beyond the EU (online), 25 de marzo de 2014, en http://beyondthe.eu/crimea-russia-belarus/

Eberstadt, Nicholas, "The Dying Bear", Foreign Affairs, vol. 90, núm. 6, noviembre-diciembre de 2011, pp. 95-108.

Federal Migration Service of the Russian Federation, Concept for the Russian Federation's State Policy on Migration up to 2025, 13 de junio de 2012.

Fierman, William, "Russian in Post-Soviet Central Asia: A Comparison with the States of the Baltic and South Caucasus", Europe-Asia Studies, vol. 64, núm. 6, agosto de 2012, pp. 1077-1100.

Gershman, Carl, "Former Soviet States Stand Up to Russia. Will the U.S.?", The Washington Post, 26 de septiembre de 2013.

Gessen, Masha, The Man without A Face: The Unlikely Rise of Vladimir Putin, Riverhead Trade, 2013.

Gradirovski, Sergei y Neli Esipova, "Russian Language Enjoying a Boost in post-Soviet States", Gallup Poll Briefing, 1 de agosto de 2008, en http:// www.gallup.com/poll/109228/russian-language-enjoying-boostpostsoviet-states.aspx

Hamilton, Philip, "Professor Stephen Walt on the Crisis in Ukraine", Boston Global Forum, 25 de marzo de 2014.

Herszenhorn, David, "Latvians Reject Russian as Second Language", The New York Times, 19 de febrero de 2012.

Interfax, "Parity between Belarusian, Russian Language to Be Preserved in Belarus-Lukahenko", Russian E CIS Presidential Bulletin, 31 de diciembre de 2009, en EBSCOHost http://web.a.ebscohost.com/ehost/de tail/detail?vid=9\&sid=642799ba-8284-428b-8f08-f3c580903e51\%40ses sionmgr4002\&hid $=4212 \&$ bdata $=$ Jmxhbmc9ZXMmc210ZT1laG9zdC1 saXZl\#d b=bwh\&AN=48527835

, "Up to $80 \%$ of Labor Migrants Do Not Know Russian languageFederal Migration Service”, Russia $\mathcal{E}$ CIS Business $\mathcal{E}$ Financial Newswire, 24 de diciembre de 2012, en EBSCO Host, http:/ / web.a.ebscohost. $\mathrm{com} / \mathrm{ehost} / \mathrm{detail} /$ detail?vid=12\&sid=642799ba-8284-428b-8f08f3c5 $80903 \mathrm{e} 51 \%$ 40sessionmgr4002\&hid $=4212 \&$ bdata $=$ Jmxhbmc $9 Z X M m$ c210ZT1laG9zdC1saXZl\#db=bwh\&AN=84458877

, "Russian Language Skills of Migrant Workers from Central Asia Getting Worse, Moscow Migration Service", 11 de abril de 2013, en EBSCO Host, http://web.a.ebscohost.com/ehost/detail/detail?vid= 
18\&sid=642799ba-8284-428b- 8f08f3c580903e51\%40sessionmgr4002 \&hid=4212\&bdata=Jmxhbmc9ZXMmc210ZT1laG9 zdC1saXZl\#db=b wh\&AN=86946220

—, "As of May 1 Russian Population Reaches $146 \mathrm{mln}, 2.3 \mathrm{mln}$ of them in Crimea-Rosstat", 20 de junio de 2014, en EBSCO Host, http:/ / web.a.ebscohost.com/ehost/detail/detail?vid=7\&sid=64 2799ba-8284-428b-8f08f3c580903e51\%40sessionmgr4002\&hid=4212 \&bdata $=$ Jmxhbmc9ZXMmc210ZT1laG9zdC1saXZl\#db=bwh\& $\mathrm{AN}=96689895$

Jarzynska, Katarzyna, "A New Concept of Migration Policy in Russia”, 20 de junio de 2012, Osrodek Studiow Wschodnich (sitio electrónico), http:/ /www.osw.waw.pl/en/publikacje/analyses/2012-06-20/a-newconcept-migration-policy-russia

Kelly, Lidia, "Russia May Ask Rich to Help Foot Bill for Crimea with 'Solidarity Tax'”, Reuters, 22 de julio de 2014, http:/ /www.reuters.com/ article/2014/07/22/us- ukraine-crisis-russia-tax-idUSKBN0FR1SB20 140722

Kennedy, Paul, The Rise and Fall of great Power: Economic Change and Military Conflict from 1500 to the Present, Nueva York, Random House, 1987.

Krasnolutska, Daryna y Kateryna Choursina, "Ukraine Leader Says Putin Seeks to Restore Soviet Union”, Bloomberg News, 13 de septiembre de 2014, en http:/ / www.businessweek.com/news /2014-09-12/u-dot-s-dot -widens-sanctions-on-russian-banks-energy-defense-firms (consultado el 24 de octubre de 2014).

Krymedia, "Results of Census: Population of Crimea is 2.284 Million People”, 16 de diciembre de 2014, en http:/ / en.krymedia.ru/society /3365334-Results-of-Census-Population-of-Crimea-is-2284-Million-Pe ople (consultado el 4 de mayo de 2015).

Levy, Clifford J., "Still Fighting Russia, this Time with Words", The New York Times, 23 de enero de 2011, en http:/ / www.nytimes.com/2011/01/24/ world/europe/24georgia.html?_r=0 (consultado el 5 de mayo de 2015). Lodahl, Maria, "Russia: Demographic Trends Pose Economic Problems", Economic Bulletin, vol. 37, núm. 8, agosto de 2000, pp. 255-262.

Mearsheimer, John, The Tragedy of Great Power Politics, Nueva York, W.W. Norton \& Company, 2001.

-, "Why the Ukraine Crisis Is the West's Fault", Foreign Affairs, vol. 93, núm. 5, septiembre-octubre de 2014, pp. 1-12. 
Morgenthau, Hans, Politics among Nations: The Struggle for Power and Peace, Nueva York, Knopf, 1948.

National Review, "Putin's Perilous Overreach", 7 de abril de 2014.

Orr, Robert, "Why Crimea Matters to Russia”, Blog, 3 de marzo de 2014, en http://blogs.ft.com/the-world/2014/03/why-crimea-matters-to-rus sia/ (consultado el 30 de noviembre de 2014).

Parfitt, Tom, "Russia's Population Crisis", The Lancet, vol. 365, 26 de febrero de 2005, pp. 743-744.

Rybakovskii, Leonid, "The Demographic Development of Russia and Its Dominance in the First Quarter of the Twenty-First Century", Sociological Research, vol. 51, núm. 5, septiembre-octubre de 2012, pp. 64-73. , "Russian Population Dynamics and Its Components in 200125”, Russian Social Science Review, vol. 54, núm. 4, julio-agosto de 2013, pp. 50-62.

Schwartz, Paul, "Crimea's Strategic Value to Russia”, 18 de marzo de 2014, Center for Strategic \& International Studies (sitio web), en http:// csis.org/blog/crimeas-strategic-value-russia (consultado el 30 de noviembre de 2014).

Shapiro, Ben, "Putin's Next 4 Targets", Breitbart (online), 18 de marzo de 2014, en http://www.breitbart.com/national-security/2014/03/18/ putin-four-invasions/ (consultado el 29 de noviembre de 2014).

Simon, Luis, "Interview with Kenneth Waltz", 15 de marzo de 2013, en http:/ / www.europeangeostrategy.org/2013/03/interview-kennethwaltz/ (consultado el 24 de octubre de 2014).

Spencer, Christopher, "Crimea Proves Political Realism Is Still Dominant", Guardian Liberty Voice, 23 de marzo de 2014.

Stenin, Andrei, "Russia Has World's $2^{\text {nd }}$ Largest Number of ImmigrantsUN Study”, Sputnik News (online), 12 de septiembre de 2013, en http://sputniknews.com/russia/20130912/183384782.html (consultado el 29 de noviembre de 2014).

Stratfor, "Ukraine: Russia Looks Beyond Crimea", 3 de marzo de 2014, en EBSCO Host, http://web.b.ebscohost.com/ehost/detail/detail?vid= 4\&sid=2ec9dfea-a217-41dc-a60a0491 ebe60f26\%40sessionmgr112\&hi $\mathrm{d}=105 \&$ \&data $=$ Jmxhbmc9ZXMmc210ZT1laG9zdC1saXZl\#db=bth\& $\mathrm{AN}=95421622$ (consultado el 1 de diciembre de 2014).

Tasch, Barbara, "Russia, Kazahstan, Belarus Sign Treaty Creating Huge Economic Bloc", 30 de mayo de 2014. 
“Time for Realism and Common Sense on Ukraine”, The Nation, 24 de marzo de 2014.

TV-Novosti, "Crimea to Be a Special Economic Zone with Tax Breaks", 1 de abril de 2014, http://rt.com/business/crimea-zone-tax-break-345/ (consultado el 25 de octubre de 2014a).

—, "Russia, Belarus, Kazakhstan Sign 'Epoch' Eurasian Economic Union”, 29 de mayo de 2014, en http:/ /rt.com/business/162200-rus sia-bealrus-kazakhstan-union/ (consultado el 25 de octubre de 2014).

United Nations, Demographic Policy in Russia: From Reflection to Action, Moscú, United Nations in Russia, 2008.

Walt, Stephen, "Why Arming Kiev Is a Really, Really Bad Idea", Foreign Policy, 9 de febrero de 2015.

Waltz, Kenneth, "The Emerging Structure of International Politics", International Security, vol. 18, núm. 2, otoño de 1993, pp. 44-79.

Wilk, Andrzej, "The Military Consequences of the Annexation of Crimea”, Osrodek Studiów Wschodnich, 19 de marzo de 2014, véase http:/ / www.osw.waw.pl/en/publikacje/analyses/2014-03-19/military-consequences-annexation-crimea (consultado el 5 de noviembre de 2014).

Zakaria, Fareed, From Wealth to Power: The Unusual Origins of America's World Role, Princeton, Princeton University Press, 1998. 